\section{AEET}

Ecosistemas 21(3):118-120 [Septiembre-Diciembre 2012] Doi.: 10.7818/ECOS.2012.21-3.19

Artículo publicado en Open Access bajo los términos de Creative Commons attribution Non Comercial License.

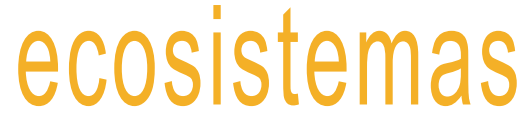

REVISTA CIENTÍFICA DE ECOLOGÍA Y MEDIO AMBIENTE

\title{
Respuestas fisiológicas de Bituminaria bituminosa frente a sequía y metales pesados
}

\author{
D. Martínez-Fernández ${ }^{1, *}$ \\ (1) Departamento de Recursos Naturales, Instituto Murciano de Investigación y Desarrollo Agrario y Alimentario (IMIDA), Estación Sericícola, Calle Mayor \\ s/n, La Alberca, 30150 Murcia, España.
}

* Correpondencia: [domingo.marfer@gmail.com]

> Recibido el 18 de octubre de 2012, aceptado el 30 de noviembre de 2012.

Martínez-Fernández, D. (2012). Respuestas fisiológicas de Bituminaria bituminosa frente a sequía y metales pesados. Ecosistemas 21(3):118-120. Doi.: 10.7818/ECOS.210.21-3.19

Bituminaria bituminosa (L.) C.H. Stirton es una especie perteneciente a la familia de las Leguminosas (Fabaceae), conocida con los nombres comunes de tedera, trébol hediondo o hierba pestosa (en inglés "Arabian pea"). Antes de adquirir su nombre científico actual, fue nombrada con los seudónimos taxonómicos Psoralea bituminosa (L.) y Aspalthium bituminosum (L.) Kuntze. Todos sus nombres hacen referencia al carácter que la convierte en una de las leguminosas más fáciles de reconocer, además de por sus características flores violáceas (Fig.1 (A)), por su inconfundible olor a betún, y de ahí su nombre, que puede percibirse por ejemplo cuando se machacan sus foliolos entre los dedos. Es una planta de porte arbustivo muy frecuente en los márgenes de caminos y carreteras.

La especie estudiada en esta tesis presenta tres intrataxones que pueden colonizar un amplio rango de bioclimas (Fig. 1 (B)). El más común es la variedad bituminosa, que aparece en toda la Cuenca Mediterránea e Islas Canarias (precipitación anual de 200 $800 \mathrm{~mm}$ ), mientras que las variedades albomarginata (120-180 $\mathrm{mm}$ ) y crassiuscula (zonas de alta montaña y fríos inviernos) únicamente crecen de manera natural en las Islas Canarias.

El interés de su estudio nace en sus múltiples aplicaciones potenciales. Se ha utilizado de manera tradicional en la producción de alimento para ganado en las Islas Canarias, y existe un creciente interés internacional por el uso forrajero de $B$. bituminosa, utilizándose actualmente como planta modelo en programas de producción de forraje en Australia (Real y Verbyla 2010). Por otro lado, B. bituminosa también crece de manera natural en suelos contaminados con elevadas concentraciones de metales pesados (MPs), como en la Sierra Minera de La Unión (Murcia, España) (Walker et al. 2007), por lo que resulta muy relevante evaluar su aplicabilidad en la fitorremediación en este tipo de suelo con clima semiárido. Finalmente, otro de sus usos está relacionado con el hecho de que los frutos y hojas de $B$. bituminosa pueden llegar a acumular altas concentraciones de furanocumarinas (FCs): cerca de $4000 \mathrm{\mu g} \mathrm{g}^{-1} \mathrm{PS}$ de psoraleno, y $10000 \mathrm{\mu g} \mathrm{g}^{-1} \mathrm{PS}$ de angelicina (Martínez et al. 2010), compuestos de amplia aplicación farmacéutica.
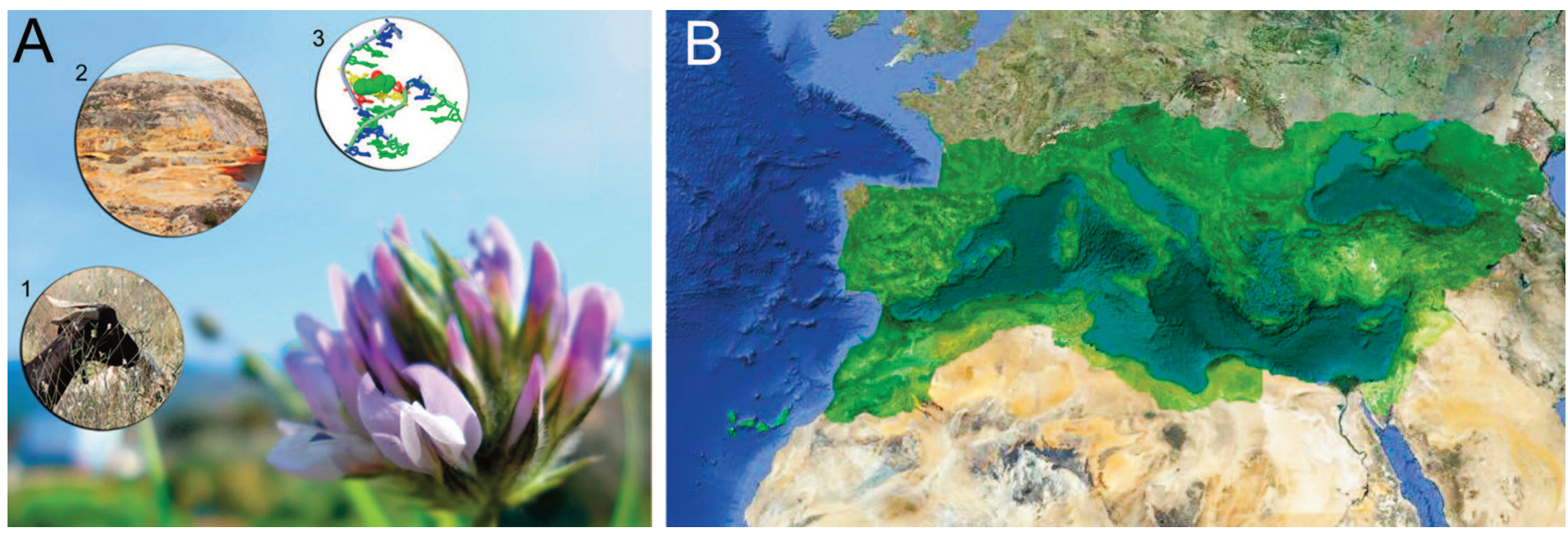

Figura 1. (A) Inflorescencia de Bituminaria bituminosa y representación de sus tres usos: (1) Forraje; (2) Fitorremediación; (3) Farmacia. (B) Distribución de la especie B. bituminosa, señalada con color verde sobre el mapa de la cuenca del Mar Mediterráneo. 


\section{Respuestas de $B$. bituminosa frente a sequía}

Aunque $B$. bituminosa presenta características que la catalogan como una especie que posee una elevada resistencia constitutiva a la sequía, la selección de cada variedad dependerá del uso en el que se pretendan utilizar, detectándose con esta tesis diferencias respecto sus respuestas fisiológicas entre las variedades estudiadas (Tabla 1). En cuanto a sequía, se realizó un primer ensayo en macetas de 1.5 I en cámara de cultivo (58 días), con suelo procedente de la finca experimental del IMIDA (Walker et al. 2007), donde posteriormente se realizaría un ensayo de campo durante la estación estival. El tratamiento en ambos ensayos consistió en la interrupción del aporte hídrico respecto plantas control regadas. Para conocer su transporte de agua a través de las raíces, se realizó un tercer experimento en hidropónico (42 días), imponiendo diferentes grados de estrés hídrico gracias a la adición de polietilengicol (PEG 8000 ) al medio líquido nutritivo. Las concentraciones elegidas fueron $0 \%$ PEG, $4.5 \%$ PEG y $9 \%$ PEG (equivalente a un potencial creado por $40 \mathrm{mM} \mathrm{NaCl}$ ).

Se comprobó que la variedad albomarginata (población Famara, Lanzarote) consiguió que sus plantas estresadas alcanzaran la mayor biomasa, por lo que es la más adecuada para la producción de forraje, manteniendo su contenido relativo de agua, aumentando su relación raíz:parte aérea, y conservando una gran conductividad hidráulica de sus raíces. Se comprobó que esta variedad es más tolerante y está mejor adaptada para soportar periodos secos, tanto en verano como durante el resto del año, evitando el estrés interno a través del mantenimiento de sus relaciones hídricas. La variedad crassiuscula (población Boca de Tauce, Tenerife) se comporta de manera similar frente a sequía que albomarginata, pero con menor biomasa y menor área foliar espe- cífica (hojas más gruesas), demostrando la resistencia constitutiva de la especie frente a sequía por no tratarse de una variedad expuesta a sequía durante su ciclo de vida normal. La variedad bituminosa (poblaciones La Perdiz y Llano del Beal, ambas de la Región de Murcia) es más sensible a sequía por ser menos eficiente para evitar el estrés. Su estrategia frente a la sequía es el sometimiento o tolerancia al estrés interno, con grandes cambios osmóticos, pero sin que estos provoquen grandes efectos en el crecimiento.

\section{B. bituminosa en la fitoremediación de ecosistemas afectados por MPs}

Como consecuencia de la actividad minera llevada a cabo durante siglos en La Unión, existen en la Región de Murcia más de $40 \mathrm{~km}^{2}$ de terreno estéril con altas concentraciones de MPs (As, $\mathrm{Cu}, \mathrm{Pb}, \mathrm{Zn}$ ) (Fig. 2 (A)). La erosión afecta fuertemente a estos suelos, altamente inestables y desprovistos de vegetación, por lo que el establecimiento de una cobertura vegetal permitiría estabilizar físicamente los suelos (fitoestabilización), y minimizar la erosión y diseminación de los contaminantes (Méndez y Maier 2008). B. bituminosa es una de las especies silvestres de los suelos de La Unión con tolerancia a MPs (Walker et al. 2007). Como en sequía, se realizaron ensayos a tres niveles de experimentación. Inicialmente un ensayo en maceta (60 días), con un suelo altamente contaminado procedente de El Llano del Beal, un suelo moderadamente contaminado de San Ginés de la Jara, y un suelo limpio de metales usado como control. En el mismo experimento se evaluó el efecto de diferentes enmiendas (compost, fertilizante, purín de cerdo) sobre el desarrollo las plantas y la biodisponibilidad de los metales en el suelo. Los ensayos de campo se realizaron sobre ambos suelos

Tabla 1. Poblaciones de la especie B. bituminosa estudiadas en esta tesis doctoral.

\begin{tabular}{|c|c|c|c|c|c|}
\hline \multirow[b]{2}{*}{ Variedad } & \multirow[b]{2}{*}{ Población } & \multicolumn{4}{|c|}{ Origen } \\
\hline & & Localidad & Precipitación anual (mm) & Altitud (msnm) & $\begin{array}{c}\mathrm{T}^{\mathrm{a}} \text { media meses más fríos } \\
\text { y calurosos (oC) }\end{array}$ \\
\hline \multicolumn{6}{|c|}{ ENSAYOS SEQUÍA } \\
\hline albomarginata & Famara & Famara, Lanzarote & $150-350$ & 600 & $11.1 / 22.8$ \\
\hline crassiuscula & Boca de Tauce & Mt. Teide, Tenerife & $165-500$ & 2200 & $4.0 / 17.4$ \\
\hline bituminosa & Llano del Beal & Llano del Beal, Murcia & $200-400$ & 300 & $9.7 / 26.1$ \\
\hline bituminosa & La Perdiz & Sierra Espuña, Murcia & $200-350$ & 850 & $5.9 / 25.8$ \\
\hline \multicolumn{6}{|c|}{ ENSAYOS METALES PESADOS } \\
\hline bituminosa & LA & Mijas, Málaga & $400-600$ & 1000 & $6.1 / 28.1$ \\
\hline bituminosa & $\mathrm{C} 2$ & La Esperanza, Murcia & $200-400$ & 200 & $9.7 / 26.1$ \\
\hline
\end{tabular}
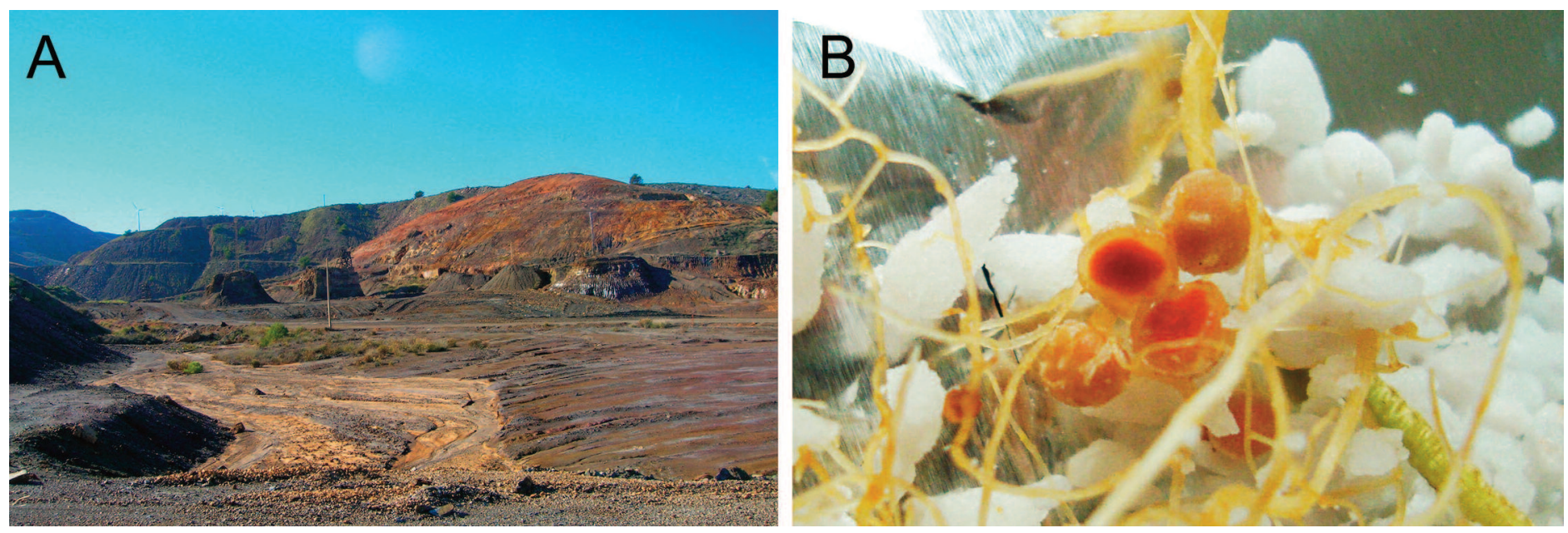

Figura 1. (A) Paisaje estéril como resultado de la actividad minera en La Unión (Murcia, España). (B) Nódulos activos de bacterias fijadoras de nitrógeno (cepa LB11) obtenidos tras inoculación de raíces de B. bituminosa usando bacterias aisladas a partir del propio suelo contaminado. 
contaminados durante 2 años de duración. En hidropónico, se ejecutaron diferentes ensayos individuales (50 días) con los metales más abundantes y disponibles en estos suelos $(4.4 \mu \mathrm{M} \mathrm{Cd}, 7.8 \mu \mathrm{M}$

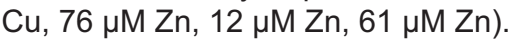

La especie $B$. bituminosa mostró una alta tolerancia a los metales, de la cual podría decirse que posee resistencia en comparación con otras especies, y en especial la población "C2" (Tabla 1), procedente de un suelo contaminado por MPs cercano a la antigua zona minera. Dicha población "C2" es menos sensible a altos niveles tisulares de metales, especialmente a Zn, que la población " $L A$ ", procedente de suelo limpio de MPs, inhibiendo menos su crecimiento, tanto en parte aérea como en raíz. Con esta tesis se ha comprobado que podría considerarse a $B$. bituminosa como una especie apropiada para una etapa inicial en la revegetación de suelos no salinos, moderadamente contaminados por MPs, y con pH en el intervalo neutro-alcalino ( $\mathrm{pH}$ 6.5-8.0). Además, se trata de una especie capaz de formar nódulos con bacterias simbiontes que le permiten fijar $\mathrm{N}_{2}$ atmosférico y mejorar la fertilidad del suelo, algo especialmente de interés para la revegetación de sitios contaminados, normalmente muy pobres en nutrientes. Durante esta tesis se encontró e identificó una gran diversidad genética de cepas que nodulan en las raíces de $B$. bituminosa, como bacterias de los géneros Phylobacterium y Rhizobium, y la especie Mesorhizobium ciceri. El aislado LB11 (http://www.ncbi.nlm.nih.gov/nuccore/JN378715.1), procedente de suelos contaminados de La Unión (Fig. 2 (B)), podría ser una cepa aplicable en estos suelos, gracias a su tolerancia a la presencia de MPs, y su gran capacidad para fijar nitrógeno hasta las plantas.

\section{Síntesis de compuestos de interés farmacéutico por $B$. bituminosa}

Las FCs deben su actividad biológica a que reaccionan fotoquímicamente con los ácidos nucleicos (particularmente ADN) en presencia de la luz ultravioleta. Por eso tienen aplicación en el campo de la medicina (terapias PUVA contra la psoriasis, melanoma, etc.) y biología molecular. Durante ensayos frente a sequía y MPs, las poblaciones canarias presentaron mayor proporción de psoraleno, mientras que las poblaciones peninsulares mostraron mayor proporción de angelicina. La presencia de distintos MPs en el medio afecta de diferente manera a las relaciones hídricas, y a su vez a la acumulación de FCs, sin que la relación psoraleno:angelicina se vea afectada por la exposición a MPs. La alta acumulación de FCs hace de $B$. bituminosa una candidata adecuada para la producción de estos compuestos a escala de campo. Para este propósito, la población "C2" podría ser muy adecuada y rentable debido a su alta acumulación de psoraleno, producto de alto valor comercial. Asumiendo los niveles de psoraleno obtenidos en los ensayos de esta tesis (máximos de $6000 \mathrm{\mu g} \mathrm{g}^{-1} \mathrm{PS}$ en hoja), para una producción en campo de $B$. bituminosa de 20-40 toneladas de materia verde $\mathrm{ha}^{-1} \mathrm{año}^{-1}$, podrían obtenerse entre $12-24 \mathrm{Kg}$ de psoraleno ha-1 año-1.

\section{Referencias}

Martínez, S., Correal, E., Real, D., Ortuño, A., del Río J.A. 2010. Bituminaria bituminosa: a source of furanocoumarins of pharmaceutical interest. En: A.S. Awaad, J.N. Govil, V.K. Singh (eds). Recent Progress in Medicinal Plants. Vol 27. Drug Plants I, pp. 310-322.. Studium Press LLC, Houston, USA.

Méndez, M.O., Maier, R. 2008. Phytostabilization of mine tailings in arid and semiarid environments - an emerging remediation technology. Environmental Health Perspectives 116:278-283.

Real, D., Verbyla, A. 2010. Maximizing genetic gains using a "plant" model in the Tedera (Bituminaria bituminosa var. albomarginata and var. crassiuscula) breeding program in Australia. Options Méditerranéennes A 92:87-95

Walker, D.J., Bernal, M.P., Correal, E. 2007. The influence of heavy metals and mineral nutrient supply on Bituminaria bituminosa. Water, Air, and Soil Pollution 184:335-345.

\section{DOMINGO MARTÍNEZ FERNÁNDEZ}

\section{Respuestas fisiológicas de Bituminaria bituminosa frente a sequía y metales pesados}

Tesis Doctoral

Departamento de Recursos Naturales del Instituto Murciano de Investigación y Desarrollo Agrario y Alimentario (IMIDA). Departamento de Producción Vegetal de la Universidad Politécnica de Cartagena (UPCT)

Julio 2012

Director: Dr. David-James Walker

Disponible en: http://hdl.handle.net/10317/2765

\section{Publicaciones resultantes de la Tesis}

Bernal, M.P., Clemente, R., de la Fuente, C., Pardo, T., Alburquerque, J.A., Bustamante, M.A., Martínez-Alcaraz, I., Martínez-Fernández, D., Walker, D.J. 2010. Nuevas opciones y revalorización del purín porcino. Tierras de Castilla 174:54-57

Clemente, R., Walker, D.J., Pardo, T., Martínez-Fernández, D., Bernal, M.P. 2012. The use of a halophytic plant species and organic amendments for the remediation of a trace elements-contaminated soil under semi-arid conditions. Journal of Hazardous Materials 223-224:63-71.

Martínez-Fernández, D., Walker, D.J. 2012. The effects of soil amendments on the growth of Atriplex halimus and Bituminaria bituminosa in heavy metal-contaminated soils. Water, Air, and Soil Pollution 223:63-72.

Martínez-Fernández, D., Walker, D.J., Romero, P., Correal, E. 2010. The physiology of drought tolerance in Tedera (Bituminaria bituminosa). Options Méditerranéennes A 92:155-159.

Martínez-Fernández, D., Walker, D.J., Romero-Espinar, P., Flores, P., del Río, J.A. 2011. Physiological responses of Bituminaria bituminosa to heavy metals. Journal of Plant Physiology 168:2206-2211.

Martínez-Fernández, D., Walker, D.J., Romero, P., Martínez-Ballesta, M.C., Correal, E. The response of the leguminous fodder plant Bituminaria bituminosa to water stress. Journal of Agronomy and Crop Science (DOI: 10.1111/j.1439-037X.2012.00515.x).

Walker, D.J., Martínez-Fernández, D., Correal, E., Romero-Espinar, P., del Río, J.A. 2012. Accumulation of furanocoumarins by Bituminaria bituminosa in relation to plant development and environmental stress. Plant Physiology and Biochemistry 54:133-139. 